\title{
GENDER VARIATION OF CLAVICLE IN EASTERN ODISHA
}

\author{
Gyanraj Singh ${ }^{1}$, Sudeepa Das *2, Satyanarayan Shamal ${ }^{3}$, Minati Patra ${ }^{4}$.

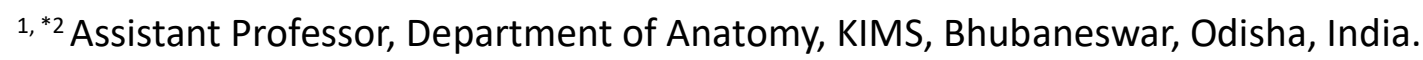 \\ ${ }^{3,4}$ Professor, Department of Anatomy, KIMS, Bhubaneswar, Odisha, India.
}

\section{ABSTRACT}

In clavicle the mid shaft circumference is considered as a consistent indicator for determining the sex however the same when combined with length increases its accuracy. The objective of this study was to determine the gender variation in adult dry human clavicles in Eastern Odisha population and to determine variations between clavicles of right and left side. An observational study was done on 100 dry clavicles of known sex, in the Department of Anatomy, KIMS. There was significant difference between the lengths of male and female clavicles and also the difference in mid shaft circumference between male and female clavicle was significant $(p<0.001)$. The findings of this study will be useful for sex determination of human skeletal remains.

KEY WORDS: Clavicle, Mid shaft circumference, sex determination.

Corresponding Author: Dr. Sudeepa Das, Assistant Professor, Department of Anatomy, KIMS, Bhubaneswar, Odisha, India. E-Mail: sudeepa.das@kims.ac.in

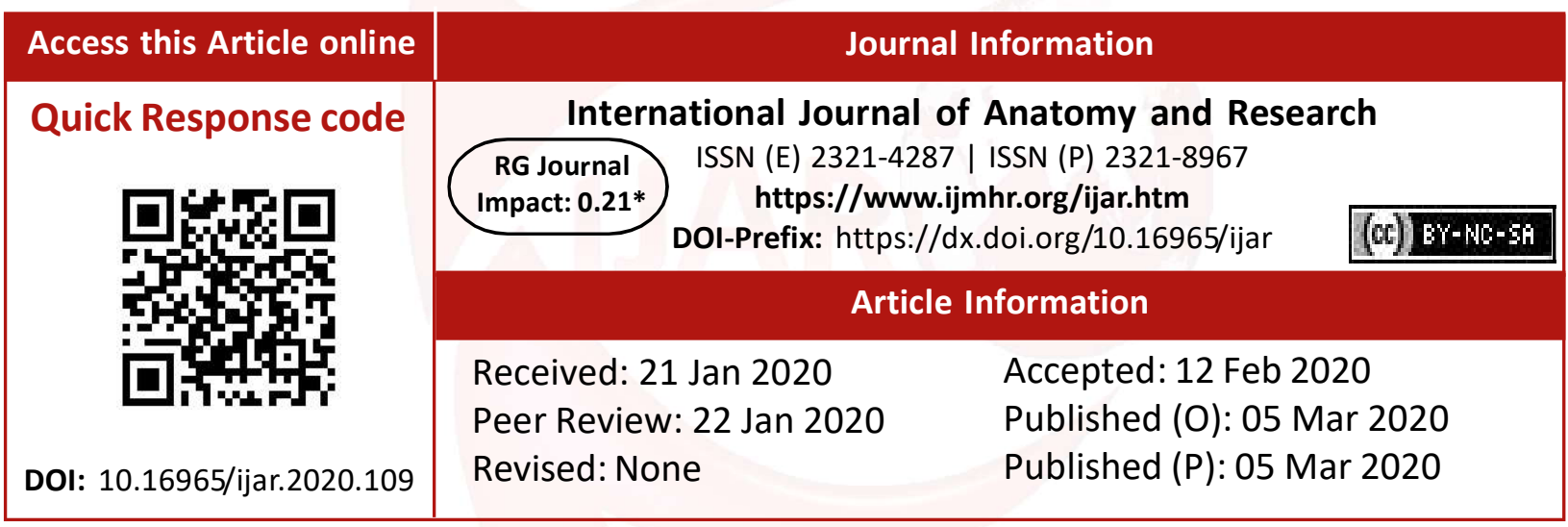

\section{INTRODUCTION}

In forensic anthropology the skeletal remains serve as a vital element for gender estimation [1]. It reduces the chances of possible matching upto fifty percent i.e. whether it is either male or female [2]. The skeletal remnants such as pelvis,skull, clavicle, limb bones, sternum, and patella are being used for identification of the unknown individuals [3].

The clavicle, being wholly subcutaneous is extending laterally and more or less horiziontally from the manubrium to the acromion across the neck [4]. The clavicles in case of females is thinner,shorter, smoother and less curved with its acromial end lower than the sternal end. In case of males it is either in level with or slightly higher than the sternal end when the arm is swinging by the side. In clavicle the mid shaft circumference is considered as a consistent indicator for determining the sex however the same when combined with its weight and length increases its accuracy [5,6]. Different levels of accuracy have been reported for gender determination using clavicle. These anthropometric measurements are unique in each race for different bones and specific geographical territory [3].

\section{OBJECTIVES OF THE STUDY}

1. To determine the gender variation in adult dry human clavicles in Eastern Odisha population.

2. To determine variations between clavicles of right and left side.

\section{MATERIALS AND METHODS}

An observational study was done on 100 dry clavicles of known sex, in the Department of Anatomy, KIMS. 57 male clavicles (Right-31 and Left-26) and 43 female clavicles (Right-24 and Left-19) were selected for the study. Mid point of the shaft of the clavicle was marked after 
measuring the total length of the clavicle. The circumference of the clavicle at its mid point was measured by using a malleable wire and digital vernier caliper. Measurements were taken three times at different time intervals without reference to the previous measurements. Mean \pm Standard Deviation of lengths and mid shaft circumference of clavicles was calculated for both sides and both sexes using statistical software. Variation between both sides and both sexes was estimated. A T-test $p$-value $<0.05$ was considered to be significant.

Inclusion criteria: Adult dry clavicle with completed ossification, No deformity/signs of injury/tumor/pathological conditions.

Exclusion Criteria: Fractured/mutilated clavicles. Degraded and deformed clavicles. Non fusion of the secondary centre of clavicle.

Duration of study: 6 months

Fig. 1: Dry Clavicles used for the study.

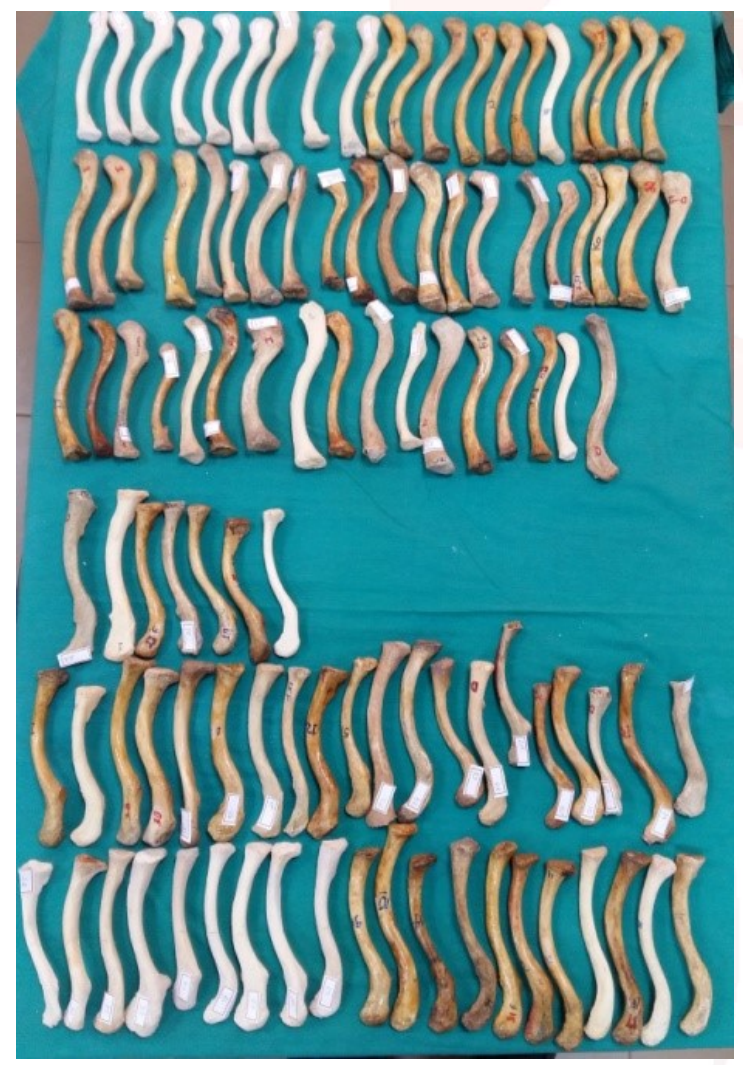

Fig. 2: Measurement of length of clavicle.

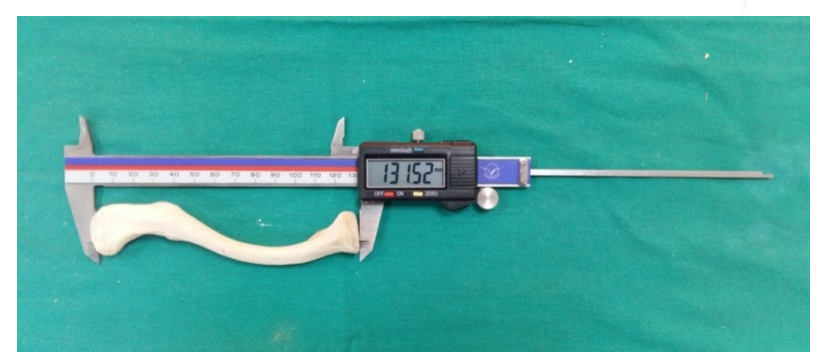

Int J Anat Res 2020, 8(1.3):7386-89. ISSN 2321-4287
Fig. 3: Mid shaft circumference measurement.

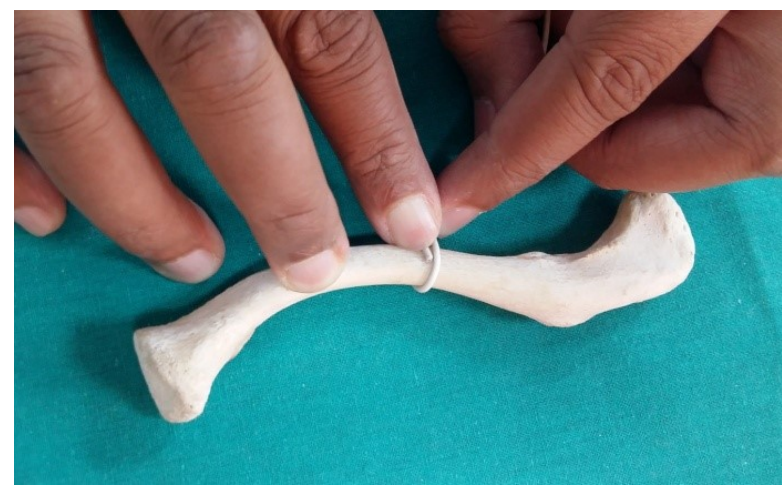

Fig.4: Measurement of Mid shaft circumference.

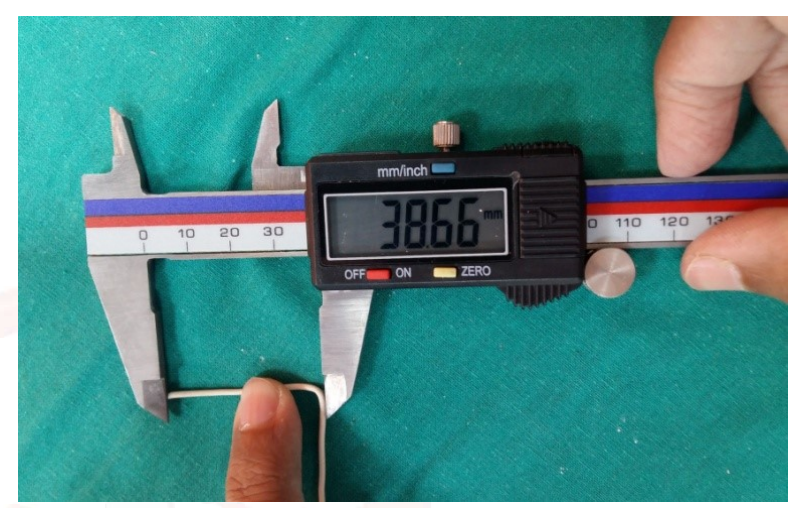

RESULTS

The length of male clavicles was found to be $143.28 \pm 4.67 \mathrm{~mm}$. on the right side and $142.84 \pm 4.67 \mathrm{~mm}$. on the left side. Female clavicles measured $128.37 \pm 5.86 \mathrm{~mm}$. on the right side and $127.52 \pm 5.96 \mathrm{~mm}$. on the left side. There was no significant difference observed between right and left sides. (Table 1)

The average length of male clavicles was calculated to be $143.08 \pm 4.64 \mathrm{~mm}$. and female clavicles was calculated to be $127.99 \pm 5.84 \mathrm{~mm}$. There was significant difference between the lengths of male and female clavicles $(p<0.001)$. (Table 1)

The mid shaft circumference in male clavicles was found to be $42.83 \pm 2.19 \mathrm{~mm}$. on right side and $42.14 \pm 2.01 \mathrm{~mm}$. on left side. In females the mid shaft circumference was found to be $37.67 \pm 1.82 \mathrm{~mm}$. on right side and $37.22 \pm 1.42$ $\mathrm{mm}$. on left side. There was no significant difference between two sides. (Table 2)

The average mid shaft circumference of male clavicles was calculated to be $42.52 \pm 2.12 \mathrm{~mm}$. and in female clavicles to be $37.47 \pm 1.65 \mathrm{~mm}$. The difference in mid shaft circumference between male and female clavicle was significant $(p<0.001)$. (Table 2$)$ 
Table 1: Lengths (in $\mathrm{mm}$.) of clavicles in male and female (Mean \pm SD).

\begin{tabular}{|c|c|c|c|c|}
\hline \multicolumn{2}{|c|}{ Male } & \multicolumn{2}{|c|}{ Female } & \multirow{4}{*}{$\begin{array}{l}p \text { - value } \\
<0.001\end{array}$} \\
\hline Right & Left & Right & Left & \\
\hline $143.28 \pm 4.67$ & $142.84 \pm 4.67$ & $128.37 \pm 5.86$ & $127.52 \pm 5.96$ & \\
\hline \multicolumn{2}{|c|}{$143.08 \pm 4.64$} & \multicolumn{2}{|c|}{$127.99 \pm 5.84$} & \\
\hline
\end{tabular}

Table 2: Mid shaft circumference (in $\mathrm{mm}$.) of clavicles in male and female (Mean \pm SD).

\begin{tabular}{|c|c|c|c|c|}
\hline \multicolumn{2}{|c|}{ Male } & \multicolumn{2}{|c|}{ Female } & \multirow{4}{*}{$\begin{array}{l}\mathrm{p} \text { - value } \\
<0.001\end{array}$} \\
\hline Right & Left & Right & Left & \\
\hline $42.83 \pm 2.19$ & $42.14 \pm 2.01$ & $37.67 \pm 1.82$ & $37.22 \pm 1.42$ & \\
\hline \multicolumn{2}{|c|}{$42.52 \pm 2.12$} & \multicolumn{2}{|c|}{$37.47 \pm 1.65$} & \\
\hline
\end{tabular}

\section{DISCUSSION}

Gender and side variations in clavicle have been observed by many researchers in different parts of India and in differents parts of the world. Manjula et al (2017) [7] had observed the lengths of clavicles in South India in males to be $134.57 \pm 10.26 \mathrm{~mm}$ (right), $138.44 \pm 7.58 \mathrm{~mm}$ (left) and in females $120.53 \pm 3.67 \mathrm{~mm}$ (right) and $121.78 \pm 4.61 \mathrm{~mm}$ (left). Kaewma et al (2017) [8] estimated the lengths of Thai clavicles to be $150.2 \pm 0.97 \mathrm{~mm}$ and $133.5 \pm 0.63 \mathrm{~mm}$ in males and females respectively. Ishwarkumar et al (2016) [9] found the length of male clavicles to be $153.52 \pm 8.79 \mathrm{~mm}$ (right), $151.82 \pm 10.96 \mathrm{~mm}$ (left) and in females to be $138.02 \pm 7.36 \mathrm{~mm}$ (right) and $141.04 \pm 5.72 \mathrm{~mm}$ (left). The difference in lengths between male and female clavicles was significant ( $p-0.0004)$.

Patel et al (2009) [10] did a study in Gujarat and observed the lengths of clavicles to be $141.85 \mathrm{~mm}$ (right) and $142.30 \mathrm{~mm}$ (left) in male and $125.90 \mathrm{~mm}$ (right) and $125.88 \mathrm{~mm}$ (left) in female. Jit \& Sahni (1983) [11] had found the lengths of male clavicles to be $148.00 \mathrm{~mm}$ (right) and $149.80 \mathrm{~mm}$ (left) and lengths of female clavicles to be $132.40 \mathrm{~mm}$ (right) and $134.00 \mathrm{~mm}$ (left). In another study Jit \& Singh (1966) [6] had observed the lengths of male clavicles to be $145.58 \mathrm{~mm}$ (right), $147.59 \mathrm{~mm}$ (left) and in female clavicles to be $130.36 \mathrm{~mm}$ (right) and $129.80 \mathrm{~mm}$ (left). In the present study we found the lengths of male clavicles to be $143.28 \pm 4.67$ $\mathrm{mm}$ (right), $142.84 \pm 4.67 \mathrm{~mm}$ (left) and female clavicles measured $128.37 \pm 5.86 \mathrm{~mm}$ (right) and $127.52 \pm 5.96 \mathrm{~mm}$ (left). The average lengths of male and female clavicle were $143.08 \pm 4.64 \mathrm{~mm}$ and $127.99 \pm 5.84 \mathrm{~mm}$ respectively. We observed that there was significant difference in lengths of clavicles between male and female $(p<0.001)$. (Table 3)

Table 3: Variations in Mean length of clavicle.

\begin{tabular}{|c|c|c|c|c|c|c|c|}
\hline SI. No. & Races & $\mathrm{N}$ & \multicolumn{2}{|c|}{ Mean length (mm) } & \multicolumn{2}{|c|}{ Mean length $(\mathrm{mm})$ Females } & Reference \\
\hline & & & Right & Left & Right & Left & \\
\hline 1 & $\begin{array}{l}\text { South India } \\
\text { (Trivandrum) }\end{array}$ & 120 & $134.57 \pm 10.26$ & $138.44 \pm 7.58$ & $120.53 \pm 3.67$ & $121.78 \pm 4.61$ & Manjula et al (2017) [7] \\
\hline 2 & Thai & 476 & \multicolumn{2}{|c|}{$150.2 \pm 0.97$} & \multicolumn{2}{|c|}{$133.5 \pm 0.63$} & Kaewma et al (2017) [8] \\
\hline 3 & $\begin{array}{l}\text { South Africa } \\
\text { (Durban) }\end{array}$ & 100 & $153.52 \pm 8.79$ & $151.82 \pm 10.96$ & $138.02 \pm 7.36$ & $141.04 \pm 5.72$ & $\begin{array}{c}\text { Ishwarkumar et al (2016) [9]. P- } \\
0.0004\end{array}$ \\
\hline 4 & India (Gujarat) & 216 & 141.85 & 142.3 & 125.9 & 125.88 & Patel et al (2009) [10] \\
\hline 5 & Indian & 360 & 148 & 149.8 & 132.4 & 134 & Jit \& Sahni (1983) [11] \\
\hline 6 & Indian & 348 & 145.58 & 147.59 & 130.36 & 129.8 & Jit \& Singh (1966) [6] \\
\hline 7 & Odisha (India) & 100 & $143.28 \pm 4.67$ & $142.84 \pm 4.67$ & $128.37 \pm 5.86$ & $127.52 \pm 5.96$ & Present study ( $p<0.001)$ \\
\hline
\end{tabular}

The mid shaft circumference has also been observed by various researchers to have differences. Manjula et al (2017) [7] had measured the mid shaft circumference in male clavicles to be $35.50 \pm 3.37 \mathrm{~mm}$ (right), $34.36 \pm 4.08 \mathrm{~mm}$ (left) and in female clavicles to be $26.82 \pm 2.40 \mathrm{~mm}$ (right) and $27.0 \pm 3.02 \mathrm{~mm}$ (left). Kaewma et al (2017) [8] had observed mid shaft circumference to measure $40.7 \pm 0.37$ $\mathrm{mm}$ in male and $34.9 \pm 0.28 \mathrm{~mm}$ in female clavicles.
Ishwarkumar et al (2016)[9] estimated the mid shaft circumference in male clavicle to be $38.60 \pm 3.55 \mathrm{~mm}$ (right) and $38.68 \pm 3.82 \mathrm{~mm}$ (left) and in female to be $33.58 \pm 2.52 \mathrm{~mm}$ (right) and $34.93 \pm 3.28 \mathrm{~mm}$ (left). He reported significant difference in mid shaft circumference of clavicles between male and female ( $p-0.0004)$. Patel et al (2009) [10] estimated mid shaft circumference to be $37.10 \mathrm{~mm}$ (right) and 36.44 $\mathrm{mm}$ (left) in male clavicles and $30.15 \mathrm{~mm}$ (right) and 30.16 (left) in female clavicles. Jit \& Sahni 
Table 4: Variations in Mid Shaft Circumference of clavicles.

\begin{tabular}{|c|c|c|c|c|c|c|c|}
\hline \multirow[t]{2}{*}{ Sl. No. } & \multirow[t]{2}{*}{ Races } & \multirow[t]{2}{*}{ N } & \multicolumn{2}{|c|}{$\begin{array}{l}\text { Mean Mid Shaft Circumference } \\
\qquad(\mathrm{mm}) \text { in Males }\end{array}$} & \multicolumn{2}{|c|}{$\begin{array}{l}\text { Mean Mid Shaft Circumference } \\
(\mathrm{mm}) \text { in Females }\end{array}$} & \multirow[t]{2}{*}{ Reference } \\
\hline & & & Right & Left & Right & Left & \\
\hline 1 & South India (Trivandrum) & 120 & $35.50 \pm 3.37$ & $34.36 \pm 4.08$ & $26.82 \pm 2.40$ & $27.0 \pm 3.02$ & Manjula et al (2017) [7] \\
\hline 2 & Thai & 476 & \multicolumn{2}{|c|}{$40.7 \pm 0.37$} & \multicolumn{2}{|c|}{$34.9 \pm 0.28$} & Kaewma et al (2017) [8] \\
\hline 3 & South Africa (Durban) & 100 & $38.60 \pm 3.55$ & $38.68 \pm 3.82$ & $33.58 \pm 2.52$ & $34.93 \pm 3.28$ & $\begin{array}{c}\text { Ishwarkumar et al (2016) [9] P- } \\
0.004\end{array}$ \\
\hline 4 & India (Gujarat) & 216 & 37.1 & 36.44 & 30.15 & 30.16 & Patel et al (2009) [10] \\
\hline 5 & Indian & 360 & 36.2 & 35.9 & 30.4 & 30 & Jit \& Sahni (1983) [11] \\
\hline 6 & Indian & 348 & 36.17 & 35.7 & 26.69 & 29.51 & Jit \& Singh (1966) [6] \\
\hline 7 & Odisha (India) & 100 & $42.83 \pm 2.19$ & $42.14 \pm 2.01$ & $37.67 \pm 1.82$ & $37.22 \pm 1.42$ & Present study $(p<0.001)$ \\
\hline
\end{tabular}

(1983) [11] observed that the mid shaft circumference of male clavicles was $36.20 \mathrm{~mm}$ (right) and 35.90 (left) and that of female clavicles was $30.40 \mathrm{~mm}$ (right) and $30.00 \mathrm{~mm}$ (left). Jit \& Singh (1966) [6] found the mid shaft circumference to be $36.17 \mathrm{~mm}$ (right), $35.70 \mathrm{~mm}$ (left) in male clavicles and $26.69 \mathrm{~mm}$ (right) and $29.51 \mathrm{~mm}$ (left) in female clavicles. In the present study, we found that the mid shaft circumference of male clavicles was $42.83 \pm 2.19 \mathrm{~mm}$ (right) and $42.14 \pm 2.01 \mathrm{~mm}$ (left), with average of $42.52 \pm 2.12 \mathrm{~mm}$. The mid shaft circumference of female clavicles measured $37.67 \pm 1.82 \mathrm{~mm}$ (right) and $37.22 \pm 1.42 \mathrm{~mm}$ (left), with an average value of $37.47 \pm 1.65 \mathrm{~mm}$. There was a statistically significant difference $(p<0.001)$ in the mid shaft circumference between male and female clavicles. (Table 4)

Our observations were similar to that of previous studies done in India and abroad. There was significant difference in the length and mid shaft circumference of clavicle between male and female.

\section{CONCLUSION}

This study will add a feather in sex determination of human skeletal remains in Eastern Odisha population to solve the medicolegal problems using clavicle in addition to other methods which are already in use.

Declaration: This study has been approved by Ethics Committee of KIMS, Bhubaneswar.

There is no conflict of interest. All authors have been actively involved in this study starting from planning, including collection and analysis of data, till preparation of final draft for publication.

\section{Conflicts of Interests: None}

\section{REFERENCES}

[1]. Singh J, Chavali KH. Age estimation from clavicular epiphyseal union sequencing in a Northwest Indian population of the Chandigarh region. J. Forensic Leg. Med., 2011;18(2):82-7.

[2]. DiGangi EA, Moore MK. Research methods in human skeletal biology. San Diego, Academic Press, 2013.

[3]. Akhlaghi M, Moradi B, Hajibeygi M. Sex determination using anthropometric dimensions of the clavicle in Iranian population. J. Forensic Leg. Med., 2012;19(7):381-5.

[4]. Gray's Anatomy. 38 ${ }^{\text {th }}$ edition. Churchill Livingstone. Great Britain. 1999;619.

[5]. Olivier G. Anthropologie de la claviculae; XIII, Conclusions generales. Bull. Mem Soc. Anthropol. Paris, 1956;7(5):404-47.

[6]. Jit I, Singh S. The sexing of the adult clavicles. Indian J. Med. Res., 1966;54(6):551-71.

[7]. Manjula TS, Vrijakumari CR, Kumar KV, Indira MV. Clavicle, A tool for sex determination - A study in South India. IOSR Journal of Dental and Medical Sciences., 2017;16(2):54-58.

[8]. Kaewma A, Sampannang A, Taumsuk P, lamsaard S. Morphometry of Isan-Thai Clavicles as a guide for sex determination. Int. J. Morphol., 2017;35(1):172177.

[9]. Ishwarkumar S, Pillay P, Haffajee MR, Rennie C. Sex determination using Morphometric and morphologic dimensions of the clavicle within the KwaZuluNatal population. Int. J. Morphol., 2016;34(1):244251.

[10]. Patel JP, Shah RK, Merchant SP, Nirvan AB, Shah GV. Sexing of human adult clavicle in Gujarat zone. Gujarat Med. J., 2009;64(2):40-6.

[11]. Jit I, Sahni D. Sexing the North Indian Clavicles. J. Anat. Soc. India, 1983;32(2):61-72.

How to cite this article: Gyanraj Singh, Sudeepa Das, Satyanarayan Shamal, Minati Patra. GENDER VARIATION OF CLAVICLE IN EASTERN ODISHA. Int J Anat Res 2020;8(1.3):7386-7389. DOI: 10.16965/ijar.2020.109 